\title{
The harmful haste of modern healthcare
}

\author{
Kamran Abbasi international editor, The BMJ
}

\begin{abstract}
"Nature does not hurry," said the Chinese philosopher Lao Tzu, "yet everything is accomplished." In our rush to achieve targets, profits, success, and even happiness, it seems we have pitted ourselves against nature. We allow no time for reflection. Everything needs to be done now, sooner, faster-each journey completed, each meal consumed, each promotion obtained, each status updated. When we rush we surely accomplish less. Modern medicine and healthcare are in the business of haste, to provide rapid diagnoses and innovative treatments, to deliver immediate care at every second of every day. Therein lie problems, especially when an urgent political or commercial agenda is superimposed.
\end{abstract}

In England, the anger of junior doctors at the government's plan to introduce a new contract in August 2016 is a result of the government's political expediency (doi:10.1136/bmj.h5077, doi:10.1136/bmj.h5044). Extending working hours while holding firm on salaries, and possibly reducing them, is the behaviour of a bullying employer that cares little for its employees' wellbeing. Demonising junior doctors (many of the affected doctors are advanced in their careers) is a political means to providing the truly seven day NHS that the government wishes to implement quickly without extra cost. The government's plan for junior doctors and the health service has obvious benefits for a future political marketing campaign that is based on a 24/7 health service, but the consequences for patients are poorly understood. Junior doctors are considering strike action and announcing their intention to apply for jobs overseas. Our editorialists urge caution (doi:10.1136/bmj.h5077). This is an opportunity for advocacy and to channel public support for junior doctors, so as to achieve better working conditions and, ultimately, better patient care.

Other editorialists criticise the US Food and Drug Administration's responsiveness to commercial expediency, namely industry's profit drive (doi:10.1136/bmj.h4897). Patients and doctors, we are told, want newer drugs to be available sooner. Faster regulatory approval means that patients benefit more quickly, says the industry propaganda, and the revenue that companies generate can fund more research. Evidence is clear that the FDA is reviewing new drugs more rapidly and using quicker supplemental approval for existing products (doi:10.1136/bmj.h4633, doi:10.1136/bmj.h4679). Our editorialists Donald Light and Joel Lexchin argue against this approach. They believe that the FDA has learnt little from the Vioxx disaster in the early 2000s. Drugs are approved quickly with marginal evidence of real benefit, and Canadian data show that faster review increases the risk of serious harm. The FDA and other national drug and device regulators need an alternative model where "research focuses on better medicines for patients rather than for profits."

In an issue that has authorities in its sights, Nina Teicholz's investigation exposes questionable processes, evidence synthesis, and competing interests involved in the production of the next US Dietary Guidelines for Americans (doi:10.1136/ bmj.h4962). A report underpinning the new guidelines reinforces the status quo: to eat less fat and fewer animal products and eat more plant foods, which fails to reflect much of the current science. For example, the report ignores evidence in favour of low carbohydrate diets. The concern about the report is such that the US Congress has intervened.

You may disagree with some of the strong editorial viewpoints expressed this week, but at The $B M J$ we are equally open to airing disagreement with what we publish, even with fashionable haste. The editorialists Nick Freemantle and Greta Rait (doi:10. 1136/bmj.h4843) critique data presented a day earlier by Cole and colleagues (doi:10.1136/bmj.h4708) on the significance of errors in papers reporting clinical trials and question the researchers' interpretation. The errors are not necessarily a marker of fraudulent or harmful research, as suggested by the researchers, but they do raise more fundamental questions about the rigour of journal editors and journal processes, which seems a good moment for editorial reflection. 